\title{
Female begging calls reflect nutritional need of nestlings in the hen harrier Circus cyaneus
}

\author{
Steve Redpath ${ }^{1,2,3^{*}}$ (D), Alex Thompson ${ }^{2}$ and Arjun Amar $^{2}$
}

\begin{abstract}
Background: Most birds exhibit bi-parental care with both sexes providing food for their young. Nestling signal food needs through begging. However, for some species, males rarely visit the nest, so have limited opportunity for gaining information directly from the chicks. Instead, females beg when males deliver food. We tested whether this calling signalled nutritional need and specifically the needs of the female (Breeder Need hypothesis) or that of their chicks (Offspring Need hypothesis).

Results: We observed begging and provisioning rates at 42 nests of hen harrier (Circus cyaneus) in Scotland, explored the factors associated with variation in begging rate and the relationship between begging and provisioning. We also tested the impact of food on begging and provisioning through a feeding experiment. Female begging rate increased up to a chick age of 3 weeks and then tailed off. In addition, begging increased when broods were large.

Conclusions: Our data provided support for the Offspring Need hypothesis. At nests where adlib food was provided females reduced their begging rate. These patterns suggested that female begging was an honest signal of need. However, begging continued even with adlib food and was only weakly associated with greater provisioning by males, suggesting that these calls may also play an additional role, possibly reflecting sexual or parent-offspring conflict.
\end{abstract}

Keywords: Begging behaviour, Nestlings, Provisioning behaviour, Breeder need, Offspring need, Raptors, Hen harrier, Sexual conflict

\section{Background}

Breeding birds have to decide how much time to devote to foraging versus a range of other behaviours, such as protecting their young against adverse weather or predators. These decisions are complicated when the two parents are foraging independently as each adult needs a way of assessing how hungry their chicks are. Fortunately, chicks are able to signal their hunger to their parents by making loud begging calls, and studies have suggested that these calls are reliable indicators of chick nutritional needs [10], with adults varying

\footnotetext{
* Correspondence: s.redpath@abdn.ac.uk

${ }^{1}$ Institute of Biological and Environmental Science, Aberdeen University

Zoology Building, Tillydrone Av, Aberdeen AB24 2TZ, UK

${ }^{2}$ FitzPatrick Institute of African Ornithology, DST/NRF Centre of Excellence,

University of Cape Town, Rondebosch 7701, South Africa

Full list of author information is available at the end of the article
}

their provisioning rate in response to variation in chick begging rates $[19,11,15,41]$. This honesty may, however, be context dependent, and begging might be less honest when the potential for conflict between chicks and parents is high [34].

In systems with bi-parental care, each adult can gain an assessment of chick needs during their visits to the nest. However, in some birds such as raptors and parrots it is common for one sex to rarely, if ever, visit the nest during the chick-rearing period. Instead, the female attends to the chicks and feeds them, whilst the male either drops prey on a perch nearby (eg goshawk Accipiter gentilis, peregrine Falco peregrinus, or sparrowhawk Accipiter nisus), or passes the food to the female in the air (eg harriers Circus spp.). The males of these species therefore gain little direct information about chick condition on which to base their foraging decisions. In such 
cases, males are dependent on females to provide information on chick need.

Begging calls by adult females before and during the breeding period occurs in a variety of species $[6,9,23]$. During the pre-laying and incubation stages evidence suggests that female calls signal both fertility to potential extra-pair partners and their nutritional need $[6,9,23]$. During the nestling stage, as Ellis et al. [9] pointed out, calls might reflect chick need (Offspring Need Hypothesis) or female need (Breeder Need Hypothesis). In either case, given the potential risks of calls attracting predators, we would expect female begging calls to honestly reflect the needs of the offspring or the female, and for begging call rate to be positively associated with male provisioning [23]. However, as parental investment in offspring may be costly [7, 20], females may also use their begging calls to encourage males to provide more food, so that females then invest their time in chick protection. In other words, a potential conflict may exist between the parents over how they should allocate their time to their current brood [3, 12-14].

In the hen harrier Circus cyaneus the "twiss-you" call (hereafter called the begging call) is uttered repeatedly by the female and is directed at the male, usually during and after food provisioning [44]. This call is loud and can be heard by humans up to $1 \mathrm{~km}$ away. Male hen harriers rarely visit the nest, especially when the chicks are small, but instead call to the female and pass the food to her away from the young. The time females spend at the nest declines rapidly over the first 3 weeks and then remains low until fledging [17]. This is reflected in their provisioning rates, which increase over the first three weeks then stay constant [31]. Studies of weight loss in breeding female raptors suggest that weight is maintained during incubation, but is subsequently lost during the nestling period $[25,43]$. This pattern reflects the fact that females preferentially feed their offspring, rather than themselves [25]. Given this pattern, if the Breeder Need Hypothesis was true, we would expect female begging rate to increase over the course of the nestling period as their weight loss increased. In contrast, if the Offspring Need Hypothesis was true, we would expect the rate of begging to reflect growth rates and food intake needs of the chicks and therefore to be lowest at hatching and greatest for middle nestling ages $[26,28,29]$.

To test these hypotheses and explore patterns in female begging, we first confirmed the relationship between the food intake rate of chicks and nestling age; second, we examined how female begging varied in relation to the age of chicks and brood size; third, we examined the relationship between female begging rate and male provisioning to explore whether males can adjust their provisioning in relation to female begging. Lastly, we manipulated food at some nests over two years to test whether, as expected, increased food led to decreases in begging and male provisioning rate.

\section{Methods}

Female begging was recorded at 42 breeding hen harrier nests from 1994 to 1999 on Langholm estate in southwest Scotland $\left(55^{\circ} 10^{\prime} \mathrm{N}, 2^{\circ} 58^{\prime} \mathrm{W}\right)$. Harrier nests were watched during the breeding season from hides set 6 to $10 \mathrm{~m}$ away from the nest. No nests were watched in 1997. The hides were set up once the first egg had hatched and nests were generally monitored up to the point of chick fledging (Table 1). We recorded begging behaviour at all nests during 667 watches, typically lasting 5-6 h (mean $\pm \mathrm{sd}=5.7 \pm 0.6 \mathrm{~h}$ ). During each watch we recorded the age (in weeks) and number of harrier chicks, the number of food deliveries and the number of begging calls given by females. Males provided most of the food during the first two weeks [31], with the females tending to stay close to the nest. In 1994/95 we recorded feeding patterns at nests (unpublished data). Of the 24,640 morsels of food seen consumed, the chicks ate $93.6 \%$, implying that the female preferentially fed her offspring as recorded for sparrowhawks [25].

In 1998 and 1999, 14 of the 42 nests were provided with adlib food (dead day old cockerel chick Gallus gallus domesticus and white lab rats Rattus norvegicus at a ratio of approximately 3:1) from hatching to fledging in a field experiment to test the effect of feeding on predation rates on red grouse chicks [1,32]. In the same years, 10 nests were also monitored as controls. Perches were erected on average $9 \pm 1 \mathrm{~m}$ from the nests in the fed treatment. These were visited daily and fresh food was put out. The estimated food consumed by the fed chicks ranged from $40 \mathrm{~g}$ per day at one week old to $185 \mathrm{~g}$ per day at 5 weeks old [39]. The amount of food put out per day therefore reflected these amounts. In total, 10,568 food items were placed on the perches, of which birds removed 8332 (79\%) items [32]. Of the rats and chicks seen delivered to nests during watches, females delivered 40 per $100 \mathrm{~h}$, compared to 4 by their males. All uneaten food was removed and disposed of the following day. The availability of food greatly reduced the delivery rate of wild prey by females, but not males [32].

Of the breeding adults, 9 males and 8 females were tagged. Two of these tagged males and three of the females were observed during nest watches in different years, so there was some pseudo-replication in the data. However, as the majority of birds were not tagged, it was not possible to know the extent of this potential problem.

Female harriers usually left the nest when the male approached with food and broadcast the "twiss-you" call 
Table 1 Summary of data from 42 hen harrier nests, watched during years 1994-1999

\begin{tabular}{|c|c|c|c|c|c|c|c|}
\hline$\overline{\text { Year }}$ & Nest number & Chick ages (weeks) & Number of chicks & Fed / Unfed & Time watched (hrs) & Number of Bouts & Number of calls \\
\hline 1994 & 1 & $2-6$ & $5-4$ & $U$ & 84.03 & 73 & 882 \\
\hline 1994 & 2 & $1-6$ & $4-3$ & $U$ & 105.97 & 45 & 817 \\
\hline 1994 & 3 & $1-3$ & $5-2$ & $U$ & 31.61 & 13 & 98 \\
\hline 1994 & 4 & $1-6$ & $4-2$ & $U$ & 73.46 & 52 & 1592 \\
\hline 1994 & 5 & $2-6$ & $6-4$ & $U$ & 107.32 & 63 & 2479 \\
\hline 1994 & 6 & $2-6$ & 3 & $U$ & 76.38 & 23 & 501 \\
\hline 1994 & 7 & $1-4$ & 3 & U & 66.87 & 54 & 1682 \\
\hline 1995 & 8 & $1-6$ & $5-4$ & $U$ & 99.64 & 107 & 1812 \\
\hline 1995 & 9 & $1-6$ & $4-3$ & $U$ & 105.51 & 33 & 708 \\
\hline 1995 & 10 & $1-6$ & 4 & $U$ & 91.8 & 117 & 2721 \\
\hline 1995 & 11 & $2-5$ & 4 & $U$ & 115.82 & 86 & 2692 \\
\hline 1995 & 12 & $1-5$ & 3 & $U$ & 86.14 & 114 & 2260 \\
\hline 1995 & 13 & $1-5$ & $5-3$ & $U$ & 114.94 & 114 & 2647 \\
\hline 1996 & 14 & $1-6$ & $4-2$ & $U$ & 152.22 & 99 & 2244 \\
\hline 1996 & 15 & $1-5$ & $4-3$ & $U$ & 142.22 & 112 & 1396 \\
\hline 1996 & 16 & $1-5$ & $6-4$ & $U$ & 114.14 & 88 & 3645 \\
\hline 1996 & 17 & $1-5$ & $4-3$ & $U$ & 101.16 & 117 & 3089 \\
\hline 1996 & 18 & $1-6$ & $3-2$ & U & 132.81 & 108 & 4039 \\
\hline 1998 & 19 & $1-6$ & $5-4$ & U & 87.09 & 79 & 2837 \\
\hline 1998 & 20 & $2-5$ & 3 & U & 82.95 & 98 & 3602 \\
\hline 1998 & 21 & $1-5$ & $5-2$ & $U$ & 77.67 & 56 & 1470 \\
\hline 1998 & 22 & $1-5$ & $5-4$ & $U$ & 78.34 & 85 & 2603 \\
\hline 1998 & 23 & $3-6$ & $4-2$ & $U$ & 68.58 & 45 & 1005 \\
\hline 1998 & 24 & $2-6$ & $5-3$ & U & 77.5 & 78 & 1918 \\
\hline 1998 & 25 & $1-5$ & $4-3$ & F & 70.35 & 83 & 1206 \\
\hline 1998 & 26 & $2-5$ & $4-3$ & F & 57.43 & 41 & 396 \\
\hline 1998 & 27 & $2-5$ & $3-2$ & $\mathrm{~F}$ & 58.5 & 35 & 1503 \\
\hline 1998 & 28 & $1-5$ & 5 & $\mathrm{~F}$ & 53.91 & 61 & 846 \\
\hline 1998 & 29 & $2-5$ & 2 & F & 59.5 & 66 & 1047 \\
\hline 1998 & 30 & $2-5$ & 3 & F & 70.48 & 29 & 520 \\
\hline 1998 & 31 & $1-5$ & 5 & F & 95.33 & 115 & 1780 \\
\hline 1998 & 32 & $1-5$ & 4 & $\mathrm{~F}$ & 63.99 & 56 & 704 \\
\hline 1998 & 33 & $2-5$ & $6-4$ & F & 86.77 & 61 & 1270 \\
\hline 1999 & 34 & $1-5$ & 2 & U & 78.41 & 66 & 829 \\
\hline 1999 & 35 & $1-5$ & $4-2$ & $U$ & 113.66 & 66 & 1034 \\
\hline 1999 & 36 & $1-5$ & 2 & U & 77.84 & 67 & 1871 \\
\hline 1999 & 37 & $2-5$ & 3 & U & 101.58 & 78 & 3027 \\
\hline 1999 & 38 & $1-5$ & $5-4$ & F & 95.5 & 27 & 187 \\
\hline 1999 & 39 & $1-5$ & 2 & F & 112.84 & 56 & 735 \\
\hline 1999 & 40 & $1-5$ & $4-3$ & F & 125.25 & 78 & 602 \\
\hline 1999 & 41 & $1-5$ & $4-2$ & F & 112.09 & 61 & 1174 \\
\hline 1999 & 42 & $2-5$ & 3 & $\mathrm{~F}$ & 101.58 & 46 & 496 \\
\hline
\end{tabular}

The table shows the range of chick ages at each nest during watches, the number of chicks, showing decline due to chick mortality, the total number of hours each nest was watched for, the number of bouts of begging and the total number of begging calls recorded 
to the male until returning to the nest with the prey [8]. After feeding, females sometimes left the nest to drop prey remains, collect nest material, rest away from the chicks, fly around the nest territory or hunt. In such cases if the male was still present in the area she would call until he disappeared. Usually calls were associated with a prey delivery, but sometimes the female would see the male and call at him with no exchange of food. Very occasionally, if the female was not present when the male arrived, he would drop prey at the nest and quickly leave without any female vocalisation. For the purposes of our analyses, rather than recording calls per prey delivery we recorded calls per "bout" of female calls, where a new bout was recorded if it occurred at least $10 \mathrm{~min}$ after the last female call. During each watch we recorded both the number of bouts and the number of individual calls per bout. These two measures were then used to derive an average calls per bout per watch and this was the unit for analysis.

Prey delivery rates $(\mathrm{g} / \mathrm{h})$ were calculated using the same approach as Leckie et al. [17] and Redpath et al. [33]. Briefly, we assigned a weight to each prey item brought to nests, based on estimates from the literature $[29,36]$ or our own measurements. Prey items that could not be identified were invariably small items, which were rapidly eaten and were estimated at $20 \mathrm{~g}$. As harriers are sometimes polygynous with males breeding with two or more females, and secondary females may receive less prey from their males [33], we also recorded the status of each female as monogamous, an alpha female of a bigamous male or a beta female of a bigamous male.

Fieldwork was carried out under licence from Scottish Natural Heritage.

\section{Statistical analysis}

All analyses were conducted in $\mathrm{R}$ version 3.2.3 [30]. To explore how nutritional need of chicks at nests varied with age, we estimated the amount of food ( $g$ ) delivered to the 14 nests where food was provided adlib. We assumed that food delivered reflected nestling requirements, free from any constraints imposed by other factors such as prey capture rates. We used a Linear Mixed Model with a Gaussian distribution, with biomass of food (g) delivered to the nest site per watch as the response variable. We controlled for variation in hide watch length, by fitting the length (in hours) of each hide watch as an offset in the model. We had multiple watches from the same nest in the same year and therefore to control for this we fitted nest site as a random term in the model. Additionally, to control for the potential effect of brood size, we included brood size as a fixed effect in the model. Linear mixed models were fitted using the lmer function using the lme4 package [4].
Pairwise comparisons (e.g. between chick ages) were made using the difflsmeans functions in the lmerTest package [16]. Denominator degrees of freedom were estimated using the Kenward Rogers methods using the anova function from the lmerTest package [16].

We considered patterns in female begging using the data from the 28 unfed nests. Similar to Ellis et al. [9], we took the unit of analysis as the number of calls per bout, log-transformed to meet parametric requirements of normality. Because our data came from repeated watches at nests and were unbalanced between years, we used Generalised Linear Mixed Models with a unique identifier for nest and year as random terms. Models were fitted with a normal error structure and an identity link function, and all analysis were type III. Using this approach, we explored how intensity of begging differed with chick age (week), and with different brood sizes (as a continuous variable). Explanatory variables were the brood size, the age of the chicks and the polygynous status of the female (monogamous, alpha or beta). We removed all terms that were non-significant at $P<0.1$. Results for non-significant terms are presented at the point they were removed from the model. Results for the significant terms are presented when they are included in the minimum adequate model (i.e. with all terms significant at $<0.1$ ). We took a similar approach to test the relationship between female begging rates and male deliveries during watches.

To test whether the provisioning of supplementary food reduced female begging and male deliveries, we carried out an analysis using only data from 1998 and 1999, when we experimentally fed nests, to compare begging and provisioning rates of males (grams per hour) between fed and control nests. The model structure was the same as above, except we included fed/unfed as a categorical explanatory variable. We were also interested to see whether the pattern of female calling differed between fed and unfed nests in relations to chick age and therefore also included an interaction term between feeding and chick age.

\section{Results}

The amount of food delivered by harriers to their young at 14 nests where food was provided adlib varied with chick age $\left(\chi_{4}^{2}=35.88, P<0.0001\right.$, Fig. 1a). The amount of food increased from hatching to three weeks old and then remained similar thereafter with no significant differences between three week old chicks and either four ( $\mathrm{t}$ ratio $=0.33, P=0.9$ ) or five week old chicks (t ratio $=0.56, P=0.9$ ). A similar pattern was observed the 28 nests without diversionary food. During the years of the feeding experiment, chicks at the 10 nests without diversionary food received less food than chicks at the fed nests (Fig. 1a. $F_{1,46.11}=12.7, P<0.001$ ). 


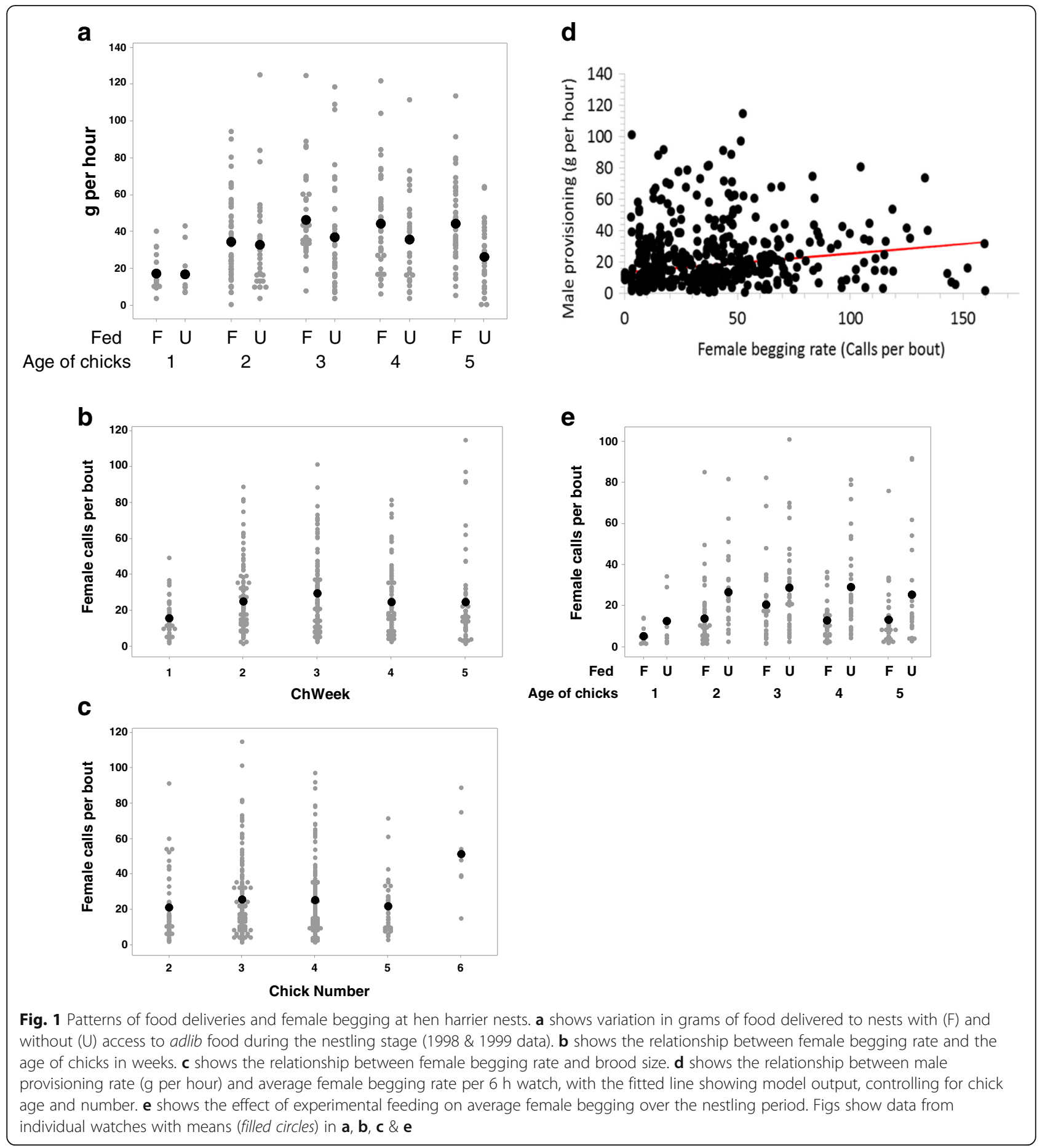

At the 28 unfed nests, female begging rate varied with chick age $\left(\mathrm{F}_{4,380}=4.85, P<0.001\right)$, and showed a similar pattern to the nutritional needs of chicks (Fig. 1b). Begging increased over the first 3 weeks of age, but in this case the rate declined significantly between chicks aged three weeks and chicks aged 5 weeks old ( $\mathrm{t}$ value $=2.97$, $\mathrm{df}=379, P=0.007)$. At these nests there was also a significant positive relationship with brood size $\left(\mathrm{F}_{1,111}=4.95\right.$,
$P=0.027$, Fig. 1c). We found no relationship between female begging rate and female breeding status $\left(\mathrm{F}_{2,23}=0.66\right.$, $P=0.66)$. After controlling for the significant effects of chick age and brood size, we found a significant positive relationship between male provisioning rates ( $\mathrm{g}$ per hour) and female begging rate $\left(\mathrm{F}_{1,385}=8.03, P<0.01\right)$, although the relationship was weak with considerable scatter (Fig. 1d). 
During the feeding experiment in 1998 and 1999 females at nests with food called significantly less than at control nests, throughout the chick rearing period $\left(\mathrm{F}_{1,57}=12.08, P<0.001\right.$, Fig. 1e $)$. The pattern of female begging with chick age was broadly similar between the nests with food and the fed and controls, and we found no interaction between chick age and treatment $\left(\mathrm{F}_{4,277}=0.6, P=0.48\right)$. There was a tendency for males at nests with food to deliver less g per hour of food than at the control nests in those years, but this was not statistically significant $\left(\mathrm{F}_{1,21}=592.8, P=0.09\right)$.

\section{Discussion}

Experimental evidence clearly indicated that begging by female harriers was associated with food intake rate. The availability of adlib food at nests greatly reduced the level of female begging. Moreover, our data provided some support for the Offspring Need Hypothesis. Female begging rates increased up to the first 3 weeks and then levelled off until fledging, in a pattern similar to the prey intake rate of the chicks. This pattern was the same at both nests with food and controls. In addition, begging rate increased with brood size, again reflecting chick need. We found less support for the Female Need hypothesis; females did not increase their calling rate throughout the nestling period, when their hunger levels would be expected to increase.

Secondary females of polygynous pairings in the hen harrier are known to receive less food from their males than monogamous and primary females, but they can compensate for this shortfall by bringing in larger prey items [33]. This compensation may have accounted for the finding that we found no association between female status and begging rates, once the age and size of the brood was accounted for.

Considerable research has investigated how offspring vary their begging investment in relation to their hunger level (reviewed in [22]). Studies have also been carried out to investigate how parents vary their provisioning efforts in relation to the efforts of their partner $[21,24,35,38]$. In hen harriers, males lack contact with their chicks and so can gain little direct information regarding offspring need. This implies there are increased possibilities in this system for females to manipulate male foraging.

It is widely recognised that communication between males and females should be honest as both have shared interests in reproductive success [40]. Indeed, there are two aspects of this system that suggest that female begging does represent an honest signal of chick need. First, begging calls are likely to be costly. One obvious potential cost lies in increased predation as a result of bouts of loud calling by females in the same way that chick begging can lead to predation [18]. Certainly field workers were guided to nests by the calls of females, implying that predators may similarly benefit. Second, females increased their begging rate when chick needs were greatest, despite this potential cost and they decreased their begging when food was provided. Similar decreases in female begging rate have been found in other systems in response to supplementary food [42, 5, 27].

However, the patterns we observed also suggest that there is some potential for conflict between the sexes. As males and females have a shared interest in fledging their chicks we would expect female begging and male provisioning to have evolved as honest signals [40]. However, we found that male provisioning was only weekly associated with female begging - a pattern in line with other studies which found a weak or no relationship [27, 23, 5]. It is possible that males have less flexibility to increase provisioning rate within seasons [32, 45], whereas females may be able to trade-off increased hunting with time spent at the nest, especially when the chicks are older. We should add one caveat to this discussion. Our data were collected in $6 \mathrm{~h}$ watches and it may be that male responses to female begging occur at a different scale.

We also found that females did not stop begging when adlib food was provided throughout the nestling period. There are a number of possible alternative explanations for this. First, females may continue to beg, albeit at a lower rate, because of uncertainty in the future environment. The fact that they have ample food today, does not necessarily mean that food will be available tomorrow, so broods need continued investment from the males. Although broods may be currently satiated, the female cannot risk that the male stops providing food in the future, otherwise she will have to spend more time hunting and therefore less time protecting her young [2]. An alternative argument is that females may need to beg at a minimum rate to reinforce male behaviour [37] and ensure continued food provisioning by the male. However, we cannot discount the possibility that female begging rate simply reflected chick begging rate and it is the chicks that are trying to manipulate their parents to keep delivering food, although they are currently satiated.

Future work could measure chick and female begging rates and experiments could focus on manipulating the signals between chicks, females and males. This could be done by feeding chicks directly (rather than providing food via females as we have done here) to reduce their nutritional needs and begging rates, or through using loudspeakers to increase the level of chick begging and/ or female begging. Similarly, female need could be manipulated through feeding females during incubation to improve their condition during the early nestling period. Environmental uncertainty could be manipulated by 
increasing variability in daily food provisioning rates by removing and adding food at nests. These studies should measure responses in male provisioning at different time scales, to see how quickly males can respond to changing begging rates.

\section{Conclusions}

Our analysis of female begging at 42 hen harrier nests provided support for the idea that female begging reflected the needs of their offspring. At nests where we experimentally made food continuously available, females reduced their begging rate, suggesting that begging was an honest signal of need. However, begging continued even with adlib food and was only weakly associated with greater provisioning by males, suggesting that these calls may also play an additional role, possibly reflecting sexual or parent-offspring conflict. Further experiments are required to tease out the contribution of these different components.

\section{Acknowledgements}

We thank the Buccleuch Estates for allowing us to work on their estate and L. Bellini, K. Bouwmann, G. Buchanan, S. Campbell, C. Cronin, E. Donnelly, F. Leckie, C. Gall, C. Hill, P. Lindley, K. Lock, M. Mainwairing, J. Martinez, R. May, D. Parish, A. Smith, A. Tharme and A. Walton for field assistance. The study was funded by Buccleuch Estates, Westerhall Estates, The Game and Wildlife Conservation Trust, The Centre for Ecology \& Hydrology, Joint Nature Conservation Committee, Royal Society for the Protection of Birds and Scottish Natural Heritage. S.R. is grateful for the King Carl XVI Gustaf guest professorship that allowed him to write this paper. None of the authors have any competing interests. We are grateful for 3 anonymous referees for their excellent, constructive comments via Peerage of Science.

\section{Funding}

Research funded by the Game and Wildlife Conservation Trust and the Centre for Ecology \& Hydrology.

\section{Availability of data and materials}

The datasets analysed during the current study are available from the corresponding author on reasonable request.

\section{Authors' contributions}

SR oversaw data collection and wrote first draft. AA and AT did the analysis and edited and wrote some sections for the finished draft. All authors read and approved the final manuscript.

\section{Competing interests}

The authors declare that they have no competing interests

\section{Consent for publication}

Not applicable

Ethics approval and consent to participate

Not applicable

\section{Publisher's Note}

Springer Nature remains neutral with regard to jurisdictional claims in published maps and institutional affiliations.

\section{Author details}

Institute of Biological and Environmental Science, Aberdeen University Zoology Building, Tillydrone Av, Aberdeen AB24 2TZ, UK. ${ }^{2}$ FitzPatrick Institute of African Ornithology, DST/NRF Centre of Excellence, University of Cape Town, Rondebosch 7701, South Africa. ${ }^{3}$ Department of Ecology,
Swedish University of Agricultural Science, Grimso Wildlife Research Station, -730 91 Riddarhyttan, SE, Sweden.

Received: 26 May 2017 Accepted: 3 June 2017

Published online: 19 June 2017

\section{References}

1. Amar A, Arroyo BE, Redpath SM, Thirgood S. Habitat predicts losses of red grouse to individual hen harriers. J Appl Ecol. 2004;41:305-14.

2. Amar A, Burthe S. Observations of predation of hen harrier nestlings by hooded crows in Orkney. Scottish Birds. 2001;22:65-6.

3. Barta Z, Houston Al, Mcnamara JM, Székely T. Sexual conflict about parental care: the role of reserves. Am Nat. 2002;159:687-705.

4. Bates D, Maechler M, Bolker B, Walker S. Fitting Linear mixed-effects models using Ime4. J Stat Softw. 2015;67(1):1-48.

5. Boucaud IC, Smith MLA, Valère PA, Vignal C. Incubating females signal their needs during intrapair vocal communication at the nest: a feeding experiment in great tits. Anim Behav. 2016;122:77-86.

6. Cantarero A, Lopez-Arrabe J, Palma A, Redondo AJ, Moreno J. Mals respond to female begging signals on need: a handicapping experiment in the pied flycatcher Ficedula hypoleuca. Anim Behav. 2014;94:167-73.

7. Clutton-Brock TH. The evolution of parental care. Princeton: Princeton University Press; 1991.

8. Cramp S, Simmons KEL, editors. Birds of the western Palearctic, Vol. 2: 116-126. Oxford: Oxford University Press; 1980

9. Ellis JMS, Langen TA, Berg EC. Signaling for food and sex? Begging by reproductive female white-throated magpie-jays. Anim Behav. 2009;78:615-23.

10. Godfray HCJ. Signalling of need by offspring to their parents. Nature. 1991; 352:328-30.

11. Heist CA, Ritchison G. Effects of variation in nestling hunger levels and begging on the provisioning behavior of male and female eastern phoebes (Sayornis phoebe). Wilson Journal of Ornithology. 2016;128:132-43.

12. Hinde CA. Negotiation over offspring care?-a positive response to partnerprovisioning rate in great tits. Behav Ecol. 2005;17:6-12.

13. Hinde CA, Kilner RM. Negotiations within the family over the supply of parental care. Proceedings of the Royal Society B: biological sciences. 2007; 274:53-60.

14. Houston Al, Székely T, McNamara JM. Conflict between parents over care. Trends Ecol Evol. 2005;20:33-8.

15. Kilner RM, Noble DG, Davies NB. Signals of need in parent-offspring communication and their exploitation by the common cuckoo. Nature, vol. 16; 1999. p. 667-72.

16. Kuznetsova A, Brockhoff PB, Christensen RHB. ImerTest: tests in Linear mixed effects models. R package version 2.0-33. 2016. https://CRAN.R-project.org/ package $=$ ImerTest

17. Leckie FM, Arroyo BE, Thirgood SJ, Redpath SM. Parental differences in brood provisioning by hen harriers Circus cyaneus. Bird Study. 2008:55:209-15.

18. Leech SM, Leonard ML. Begging and the risk of predation in nestling birds. Behav Ecol. 1997:8:644-6.

19. Leonard ML, Horn AG. Need and nestmates affect begging in tree swallows. Behav Ecol Sociobiol. 1998;42(6):431-6.

20. Lessells CM. Sexual conflict. In: levels of selection in evolution (monographs in behaviour and ecology) (Keller L, ed). Princeton: Princeton University Press; 1999:75-99.

21. Markman S, Yom-Tov Y, Wright J. Male parental care in the orange-tufted sunbird: behavioural adjustments in provisioning and nest guarding effort. Anim Behav. 1995;50:655-69.

22. Mock DW, Dugas MB, Strickler Sa. Honest begging: expanding from signal of need. Behav Ecology. 2011;22:909-17.

23. Moore SD, Rohwer VG. The functions of adult female begging during incubation in sub-Arctic breeding yellow warblers. Anim Behav. 2012;84(5): 1213-9.

24. Moreno J, Merino S, Potti J, de Leon A, Rodriguez R. Maternal energy expenditure does not change with flight costs or food avail- ability in the pied flycatcher (Ficedula hypoleuca): costs and benefits for nestlings. Behav Ecol Sociobiol. 1999:46:244-51.

25. Newton I, Marquiss M, Village A. Weights, breeding, and survival in European Sparrowhawks. The Auk, pp. 1983:344-54.

26. Olsen $P$, Doyle $V$, Boulet M. Variation in male provisioning in relation to brood size of Peregrine falcons Falco peregrinus. Emu. 1998;98:297-304. 
27. Otter KA, Atherton SE, Van Oort H. Female food solicitation calling, hunger levels and habitat differences in the black-capped chickadee. Anim Behav. 2007;74(4):847-53.

28. Palmer AG, Nordmeyer DL, Roby DD. Nestling provisioning rates of Peregrine falcons in interior Alaska. J Raptor Res. 2004;38:9-18.

29. Picozzi N. Dispersion, breeding and prey of the hen harrier Circus cyaneus in Glen dye, Kincardineshire. Ibis. 1978;120:498-509.

30. R Core Team. R: a language and environment for statistical computing. In: R foundation for statistical computing. Vienna: Austria. URL; 2015. https://www.R-project.org/.

31. Redpath SM, Thirgood SJ. Birds of prey and red grouse. Edinburgh: Stationery Office; 1997

32. Redpath SM, Thirgood SJ, Leckie FM. Does supplementary feeding reduce predation of red grouse by hen harriers? J Appl Ecol. 2001;38:1157-68.

33. Redpath S, Leckie F, Arroyo B, Amar A, Thirgood S. Compensating for the costs of polygyny in hen harriers Circus cyaneus. Behavioural Ecology and Sociobiology. 2006;60:386-91.

34. Royle NJ, Hartley IR, Parker GA. Begging for control: when are offspring solicitation behaviours honest? Trends Ecol Evol. 2002;17(9):434-40.

35. Sanz J, Kranenbarg S, Tinbergen J. Differential response by males and females to manipulation of partner contribution in the great tit (Parus major). J Anim Ecol. 2000;69:74-84.

36. Schipper WJA. A comparison of prey selection in sympatric harriers (Circus) in Western Europe. Le Gerfaut. 1973;63:17-120.

37. Schultz W, Dayan P, Montague PR. A neural substrate of prediction and reward. Science. 1997:275:1593-9.

38. Schwagmeyer P, Mock DW, Parker GA. Biparental care in house sparrows: negotiation or sealed bid? Behav Ecol. 2002;13:713-21.

39. Scottish Natural Heritage. Diversionary feeding of hen harriers on grouse moors a practical guide. Perth, Scotland: SNH Publications; 2010. http:// www.snh.org.uk/pdfs/species/hen\%20harriers.pdf

40. Searcy WA, Nowicki S. The evolution of animal communication: reliability and deception in signaling systems. Princeton, New Jersey: Princeton University Press; 2005.

41. Thompson AM, Ridley AR, Hockey PA, Finch FM, Britton A, Raihani NJ. The influence of siblings on begging behaviour. Anim Behav. 2013;86:811-9.

42. Tobias, J.A. and Seddon, N., 2002. Female begging in European robins: do neighbors eavesdrop for extrapair copulations?. Behavioral Ecology, 13(5), pp. 637-642.

43. Village A. Body weights of kestrels during the breeding cycle. Ringing Migr. 1983;4(3):167-74

44. Watson D. The hen harrier. Berkhamsted, UK: T\&AD Poyser; 1977.

45. Wiehn J, Korpimäki E. Food limitation on brood size: experimental evidence in the Eurasian kestrel. Ecology. 1997;78(7):2043-50.

\section{Submit your next manuscript to BioMed Central and we will help you at every step:}

- We accept pre-submission inquiries

- Our selector tool helps you to find the most relevant journal

- We provide round the clock customer support

- Convenient online submission

- Thorough peer review

- Inclusion in PubMed and all major indexing services

- Maximum visibility for your research

Submit your manuscript at www.biomedcentral.com/submit

) Biomed Central 